\title{
Digital Technologies as a Factor of Expanding the Investment Opportunities of Business Entities
}

\author{
M. E. Konovalova ${ }^{1(*)}$, O. Y. Kuzmina ${ }^{1}$, and S. A. Zhironkin ${ }^{2}$ \\ ${ }^{1}$ Samara State University of Economics, Samara, Russia \\ mkonovalamail.ru \\ ${ }^{2}$ Siberian Federal University, Krasnoyarsk, Russia
}

\begin{abstract}
The relevance of the study is due to the development of digitalization processes of economy, including its financial sector. The introduction of modern technologies contributes to the creation of new financial products, the emergence of fundamentally new mechanisms and ways implementing the investment process. In this regard, the article is aimed at studying the investment behavior of macroeconomic entities in the context of establishing a new economic model that creates conditions for the formation and operation of new tools and investment methods. The article is aimed at identifying and describing the features of the investment behavior of economic entities, the appearance of which is due to the transformation of motivational incentives to implement investment activities. The leading approach used in the research is systemicdialectical, which involves a comprehensive consideration of the investment process as a systemic phenomenon. The article identifies the prerequisites for changing the investment behavior of macroeconomic agents, due to the emergence of new investment tools, such as crowd-funding, crowd-investing and crowd-lending. It is proved that the introduction of digital technologies expands the investment opportunities of the subjects, which contributes to more effective implementation of their economic and institutional interests. It is shown that the ongoing evolution of the social-and-economic system, caused by digitalization, changes the traditional understanding the types of economic activity of economic agents. The article materials are of practical value for assessing the level of investment potential of macroeconomic entities; for analyzing the process of introduction and development of new technological platforms.
\end{abstract}

Keywords: Investment process - Investment tools $\bullet$ Crowd-funding • Crowd-lending $\bullet$ Crowd-investing $\bullet$ Digitalization

\section{Introduction}

The formation and development of information economy creates the prerequisites for the transformation of traditional patterns of macroeconomic agents' behavior, their motivation and ways of implementing investment strategies are changing. New technologies allow business entities to use the digital system in the field of their activity [6]. This process can include data certification (implementation of large data storage 
technologies), digitalization (conversion of information chains from analog to digital format), virtualization (splitting of reality into separate elements), and generation (reprogramming and recombination). Not only consumption and communication models are transformed, but also investment models [5], new instruments for implementing investment strategies are emerging, new sectors of the economy are being created. The relevance of the study is due to the ongoing changes in the social-and-economic system, that are based on rapid development of information (digital) technologies, which changes the existing mechanism of the investment process. The problem highlighted in the article is related to the transformation of the investment behavior of economic entities, which currently have a greater choice of investment instruments and methods of their implementation. The purpose of the study is to identify the role of digital technologies as one of the factors expanding the investment opportunities of macroeconomic agents. The implementation of this goal involves the following tasks: studying the existing digital technologies that create new investment tools; identifying features of the investment behavior of business entities; analyzing the benefits of modern investment tools for lenders and borrowers.

\section{Methodology}

The main methodological approach used in the research is systemic-dialectical. The use of this approach makes it possible to dissect the investment process as an integrated system, the individual elements of which are in dialectical interaction. The relationship between them is deeply dialectical, since it reflects the contradictory unity of the individual components of the investment process as a system. The use of a systemicdialectical approach allowed us to identify the features of the investment behavior of macroeconomic subjects in the conditions of economy digitalization.

\section{Results}

The most popular is the so-called crowd-funding, which is the interaction of individuals or legal entities, pooling their capital or other financial resources using the Internet, in order to implement a variety of projects. According to experts, the volume of operations that are carried out using alternative financing technologies (crowd-funding) will continue to grow.

Considering the process of expanding the range of investment tools through the use of new information technologies, one should pay the most attention to the mechanism of crowd-investing. Crowd-investing projects are implemented on P2P platforms. They are very diverse. These include, among other things, crowd-lending or public lending (P2P-lending), and a royalty model and joint-stock crowd-funding.

Like any other financial institution, the crowd-lending platform is a subject to risks, since even using the most advanced technology to collect data on borrowers, for example, Big Data technology, we cannot rule out the occurrence of any force majeure circumstances. Unsecured lending itself, while crowd-lending does not provide such a form of security as collateral, represents a highly risky type of financial activity. 
Another risk is directly related to the activities of an administrator or manager of crowd-lending platforms. There are no regulatory standards regarding the timing of the funds raised in the administrator's accounts, the mechanism for paying debts if the platform operator is bankrupt. The procedure of protecting the crowd-lending clients from risks is not clear enough, if such exists at all. There is a threat of using the funds acquired by criminal means, as well as the risk of lacking the complete and reliable information about the financial solvency of the participants of crowd-lending model.

Platform risks can be partially compensated by non-rigid, but, nevertheless, substantial control by financial regulators. In the US and the UK the operation of P2P lending system is possible only if it is licensed. Platforms should report on the services they provide, their profitability, and access to this data should be open. Recently, they have intensively started talking about the need for introducing a risk management procedure, toughening capital requirements, which will make it possible to impart more regulated nature to crowd-investing activities.

The volume of loans provided by means of crowd-lending platforms is growing exponentially, but they are still not able to replace banking services completely. For example, the largest American Lending Club platform, assessing the potential of P2P services in the United States, concludes that at this stage, the market for crowd-lending services has a capacity of about 500 billion US dollars, while the volume of loans issued by retail units of American banks is 4 trillion dollars, which clearly demonstrates a small share of alternative financing. However, the growth rate of direct lending is amazing - $158 \%$ per year. A similar situation is observed in Europe: the total volume of the European market for alternative financing does not exceed 3 billion euros, of which about 1 billion euros accounted for P2P lending. The Russian market for alternative financing is currently in its establishment; according to the results of 2017, 30.3 billion rubles were issued online, the average loan amount is 13,800 rubles, which indicates a slight importance of new ways to attract investments. However, according to expert estimations made by Ernst \& Young, by 2035 already $36.7 \%$ of all funds received in the form of loans will be accumulated through crowd-funding platforms. The volume of the market for alternative financing by the date indicated will amount to $\$ 178.6$ billion, taking into account annual growth by an average of 51.2\% [3].

Another form of crowd-investing is joint-stock crowd-funding. According to many researchers, this is the most popular form of public financing, providing for the investor's remuneration in the form of a share of property of an enterprise or a specific project. This type of investment attraction is based on a whole range of new tools that expand the investment opportunities of macroeconomic agents, including mining, securitization, and ICO (initial coin offering).

In the standard form, the ICO assumes the attraction of money from investors due to their involvement in the start-up, which is associated with the development and promotion of a service or platform, usually based on crypto-currency operations. At special information sites (crypto-currency forums), key financial, economic and technical information about the project (investment strategy, time of its implementation, description of the participants' team, specific activities related to the implementation of this project) appears. Using the block-chain technology, a certain number of uniqueID - digital tokens is issued. Technically, tokens are issued by adding transactions to the block-chain with an indication of their number and assigning a unique identifier. Any 
token issued during ICO is contained simultaneously on many nodes, the record of it can neither be destroyed nor changed, which allows increasing its liquidity and ensure its safety.

Participation in ICO projects is quite risky. Thus, in the first half of 2018 , the price of ICO tokens decreased by $66 \%$, which indicates high volatility, and, consequently, the risk of investing in alternative sources of financing, holding back the development of this market. Over the same period, just \$ 15 billion was raised using ICO tool. Only ten largest ICOs ensured the volume of growth in value, the rest were not profitable. The stability to this market is not added by the fact that so far no country has defined the legal ICO status, investors are not legally protected in case of a failure of the subject being financed. The anonymity of transactions and the possibility of using cryptocurrency exchanges for money laundering and financing criminal projects also confuse. Nevertheless, we noted earlier that some attempts to regulate the procedure for conducting ICOs are being made. The Government of the Russian Federation has submitted for public discussion regulations that imply the legalization of the ICO sector in order to increase the investment activity of macroeconomic agents.

The block-chain technology, on which ICO is based, can be used by macroeconomic agents not only to obtain investment through a share in a start-up, but also when performing speculative operations in the crypto-currency market. As it is well known, to ensure safety and reliability in the block-chain, either PoW (work proof) or PoS (share proof) is used. When proving work, each of the nodes, on which the cryptographic record is fixed, is involved in solving a complex computational task, the result of which is the hash code of a new block recorded in the block-chain, which is accompanied by a fee in the form of receiving crypto-currency (mining). When using share proof, every block-chain network participant has the right to assure the newly received block with his electronic signature. This right is constantly transferred from one participant to another with a probability proportional to what share of a cryptocurrency in the total volume the miner has. In this context, mining can be viewed as an activity aimed at either creating a crypto-currency or validating with the aim of obtaining remuneration in the form of crypto-currency. In any case, mining is an entrepreneurial activity, which implies the existence of not only income, but also costs. PoW miners have especially high costs.

Not only robot consultants have artificial intelligence, but also robots for highfrequency algorithmic trading, hybrid robots. Their development is associated with the growing need for customization of financial services, the need to reduce the role of intermediaries; however, at this stage their use is very limited. Robots can now be pointed to specific financial instruments; they do not perform well in volatile markets, in times of crisis, increasing the risks associated with cyber-security. The growth rate of using this kind of IT technologies in investment activity is very high, up to $70 \%$ per year. According to estimates of the National Research University "Higher School of Economics", by $2020,5 \%$ of global investment, that is 2.2 trillion US dollars, will be made with the help of robot consultants [7].

The above analysis suggests that the introduction and application of information technology significantly expands the range of both opportunities and investment tools. It modifies the traditional mechanism of savings transformation into investments, 
which leads to the emergence of new models of investment behavior of macroeconomic entities.

\section{Discussion}

Any information technology is aimed at reducing costs in the process of making a decision. Collecting information, its processing, that is, sorting, ranking, eliminating zero information (information that repeats known characteristics or is useless to make a specific decision), structuring, and also, as a final step, its evaluation is not free for the individual, since it requires time and money. Information technologies, appearing in the form of certain tools, that is, in essence, acting as means of labor, facilitate the life of economic entities, accelerate economic processes, make them more structured and transparent. It is important to understand that in the conditions of transition from industrial to post-industrial society, information becomes, firstly, an independent factor of production, and secondly, an object of commodity relations, which allows considering information technologies not only as a means of labor, but also as a subject, that is, on the one hand, they act as an instrument of labor, while, on the other, a finished product. They not only help to make the most optimal decisions, but also become the goal of human activity.

The use of information technologies often has a negative impact on economic processes due to the lack of a full material base, institutional imperfections, and weak communication links of economic entities introducing technological innovations. Vulnerability is high due to the need to balance between information security and privacy. Nevertheless, despite the negative features of using the information technologies, they are becoming more common.

If the technological mainstream of the 90s was Internet technologies $[9,14]$, then in the zero years of the twentieth century these were mobile and wireless networks [1], cloud technologies, big data technologies [4] and other digital innovations.

The process of economy digitalization is interpreted differently by representatives of the scientific community. From the point of view of some scientists, the development of the digital economy is a separate stage in the development of society associated with the global introduction of digital technologies that change the existing paradigm of coordination of economic actors. Others, on the contrary, believe that digitalization is not a separate stage of development, but an integral feature of information economy itself, since digital technology is just a new way of presenting discrete transmission of information signals [12]. There are more sophisticated approaches that reveal the essence of digital economy. So, one should distinguish the levels of digitalization. The digital economy is based on the "digital sector": organizations that, using information technology, develop digital products and services. "Digital economy" itself is that part of economy represented by companies that have business models based on digital products and services. Under "digitalized economy" is understood the use of ICT inall sectors of economy.

As we see it, the current stage in the development of society is characterized by the transformation of the role of factors of production, as a result of which information (knowledge) becomes an independent and limited resource determining many 
economic phenomena. This process underlies the establishment of information economy as a separate stage in the development of society. Digitization, on the other hand, is a specific set of new tools that extend the functionality of macroeconomic agents.

Digital technologies in the financial sector demonstrate a special intensity of introduction, changing the traditional ideas of business entities about the ways of investing. Among the technologies that have this kind of impact, block-chain, Big Data (Big Data are structured and unstructured data of huge volumes and significant diversity), cloud technologies, quantum technologies, artificial intelligence and neural networks, robotization and cryptography should be distinguished. Let us consider each of them in detail.

Thus, users of the block-chain technology act as a "collective notary", which confirms the authenticity and legitimacy of the transactions made, and this means that it is almost impossible to change and falsify information.

The problem of reliability and security of data storage is becoming increasingly important in the context of exponential growth of mass data. It is a well-known fact that in the last ten years more information has been produced than in the entire history of the mankind. Permanent growth of information volumes caused the need to create Big Data technology, which allows storing, processing and analyzing huge amounts of data, which causes a change in the principle of their analysis. The human brain is not able to accumulate and process large amounts of information, more over to identify patterns and facts of future value for an economic entity, while Big Data technology is capable of processing huge amounts of data from completely different sources in completely different formats (structured, semi-structured and unstructured data). Like the block-chain technology, Big Data provides cost savings, although it's not so much about transaction costs as IT infrastructure and software costs [8, 10, 13]. Labor costs are reduced through the use of more modern methods of data accumulation, management, and the development of behavioral strategies.

Cloud technologies play the same role in saving costs. Being data processing technologies, they assume the provision of computer resources and facilities to the user as an Internet service. The consumer can easily use his own data without thinking about the infrastructure, operating system, software. The "cloud" is the whole set of hardware and software, which allows processing and executing client requests. The prototype of cloud technology is the Internet itself, which once again underlines the diversity of cloud computing used in the information environment.

Like all informational innovations, cloud technologies have some drawbacks, especially concerning the protection of information, its security and the availability of free access to the Internet. There are also institutional constraints associated with a poorly regulated system of interaction between company-user and cloud application companies. Nevertheless, despite certain constraints, the development of cloud technologies is an irreversible process.

Quantum technologies are also associated with computational issues. According to R.V. Dushkin, quantum technologies can be divided into the following areas: quantum information transfer, quantum sensing, quantum computer, and quantum calculation itself [2]. The most developed area today is quantum information transfer, since quantum communication channels have already been created, with the help of which 
quantum key distribution protocols are implemented, which implies a completely different degree of information protection.

The expansion of the scope of quantum information transfer is limited by the computing power of modern computers. It is impossible to implement the mathematical computational model of quantum physics, using usual architecture of modern machines, even in emulation mode, since the need for computing power increases exponentially with the number of qubits. The problem could be solved when creating a quantum computer. A universal quantum computer "in hardware" has not been developed yet; there are only its prototypes that work with a small number of qubits, which does not allow implementing complex quantum algorithms. If the humanity achieved that, the tasks of modeling complex systems and chaotic dynamic processes, ranging from weather modeling to exchange trading, would be effectively solved. But at the same time, it is important to understand that quantum technologies carry certain threats, in particular, breaking of existing information systems based on modern cryptography achievements. The consequence of such transformation will be almost complete destruction of available data secrecy. Under these conditions, the trajectory of further economic development is not so definitive.

The competition principle is the basis for modern economic system, i.e. the struggle between economic entities for the right to possess resources. A significant role in this process is played by the asymmetry of information, which from the point of view of institutional approach is a definite stimulus for economic development. The absolute transparency of economic sphere during the destruction of traditional cryptography technology will lead to the transformation of existing economic system. The system can be saved, but only under the condition of progress in the field of encryption technology, which will ensure the data secrecy even when using quantum computers. This scenario is considered to be the most likely by us.

The widespread use of quantum technologies and new crypto-operation tools can lead to the appearance of what is called artificial intelligence in the scientific literature, or rather, an artificial intellectual system with self-awareness [11]. Most often, artificial intelligence means the process of mapping a set of anthropomorphic tasks on a variety of analytical tools to simulate human behavior. This concerns the modeling of creative processes, the creation of an intelligent interface, new architectural products, within which the construction of effective intelligent systems, especially robotized ones, can be implemented.

The fifth and sixth technological modes led to the transformation of human needs by changing the market criteria for evaluating goods and services. Mass commercialization of technologies implies the existence of such criteria for robots as self-learning (the use of artificial intelligence) and autonomy (robots must surpass human abilities, evolve, and independently exist in a hybrid environment). Robots are very diverse mechanisms, ranging from automation and intelligent agents to trans-border essences and automated human versions. Such differentiation is explained by the variety of environments and methods of application, the degree of specialization, mobility, and the nature of technological operations.

Robotization, artificial intelligence, cloud technologies and neural networks, quantum technologies are widely used in the financial sphere. They changed the mechanisms of banking and insurance, exchange trade, investment activity beyond 
recognition, and that is why information technologies in economic literature are often called financial technologies. In our opinion, this is not entirely correct, since information technologies are used not only in the financial sphere, but also in other areas of life, for example, medicine, construction, management, and the sphere of intellectual law. The scope of information technology is not capable of replacing its informational nature, and, therefore, the use of the term "financial technology" seems to us inappropriate.

As it was mentioned above, information technologies lead to the transformation of not only objective reality, but also a subjective assessment of the processes taking place. Motivation, targets, behavior of business entities are being changed, especially when it's time to make investment decisions. Modern information technologies underlie the creation of fundamentally new financial instruments and mechanisms that allow investment agents to carry out economic activities. There is a change in traditional ideas about the methods and forms of investment, which expands the investment opportunities of subjects, transforms the ways of interaction between investors and borrowers, and expands the range of investment tools.

\section{Conclusion}

In the course of our study the following conclusions were made:

- in transition from industrial society to post-industrial one information becomes, firstly, an independent factor of production, and secondly, an object of commodity relations, which allows us to regard information technology not only as a means of labor, but also its object in the form of a finished product;

- it is worth noting the dual nature of IT technologies impact on investment processes. The leveling of information asymmetry, the transformation of economic sphere into an absolutely transparent one, repeatedly increases the possibilities for controlling and coordinating the activities of macroeconomic actors, but completely deprives them of their development incentives. Therefore, the introduction of IT technologies in economic sphere should not be accompanied by a loss of basic market economy principles, in particular, competition;

- considering the process of expanding the range of investment tools through the use of new information technologies, it should be noted that the introduction of alternative investment methods occurs against the background of transformation of investors' subjective assessment of processes; their motivation, targets, and, consequently, the behavior change. There is an increase in investment opportunities; there are new ways of capital accumulation, and new methods of making investment decisions. 


\section{References}

1. Australia's digital economy: Future directions Canberra, Department of broadband, communications and the digital economy (2009). http://unpan1.un.org/intradoc/groups/ public/documents/apcity/unpan039471.pdf. Accessed 6 May 2019

2. Dushkin, R.V.: Review of modern state of quantum technologies. Comput. Res. Model. 10 (2), 165-169 (2018). https://doi.org/10.20537/2076-7633-2018-10-2-165-179

3. Fintech course: Market development prospects in Russia (2018). https://www.ey.com/ Publication/vwLUAssets/EY-focus-on-fintech-russian-market-growth-prospects-rus/\$File/ EY-focus-on-fintech-russian-market-growth-prospects-rus.pdf. Accessed 6 May 2019. (in Russian)

4. G20 Digital economy development and cooperation initiative (2016). http://www.g20. utoronto.ca/2016/g20-digital-economy-development-and-cooperation.pdf. Accessed 6 May 2019

5. Handel, M.: The effects of information and communication technology on employment, skills, and earnings in developing countries. Background paper for the World Development Report 2016, Washington, DC, World Bank (2015). https://blogs.worldbank.org/category/ tags/wdr-2016? page $=1$. Accessed 6 May 2019

6. Heeks, P.: Information and Communication Technology for Development. Routledge, Abingdon (2017). https://doi.org/10.4324/9781315652603

7. ISSEK HSE: New financial technologies. Trendletter 11, 1-4 (2016). https://issek.hse.ru/ data/2016/12/16/1112515468/Layout.pdf

8. Khezrimotlagh, D., Zhu, J., Cook, W.D., Toloo, M.: Data envelopment analysis and big data. Eur. J. Oper. Res. 274(3), 1047-1054 (2019). https://doi.org/10.1016/j.ejor.2018.10. 044

9. Lane, N.: Advancing the digital economy into the 21 st century. Inf. Syst. Front. 1(3), 317320 (1999). https://doi.org/10.1023/A:1010010630396

10. Mavragani, A., Tsagarakis, K.P.: Predicting referendum results in the Big Data Era. J. Big Data 6(1), 3-10 (2019). https://doi.org/10.1186/s40537-018-0166-z

11. Penrose, R.: Shadows of the Mind. A Search for the Missing Science of Consciousness. Oxford University Press, Oxford (1994)

12. Popov, E.V., Sukharev, O.S.: Digital economy: "Irrational Optimism" of management and financing. Econ. Taxes Law 11(2), 6-17 (2018).https://doi.org/10.26794/1999-849X-201811-2-6-17

13. Sohangir, S., Wang, D., Pomeranets, A., Khoshgoftaar, T.M.: Big data: deep learning for financial sentiment analysis. J. Big Data 5(1), 3-22 (2018). https://doi.org/10.1186/s40537017-0111-6

14. Tapskott, D.: The Digital Economy: Promise and Peril in the Age of Networked Intelligence. McGraw-Hill, New York (1994) 